\title{
O espaço da mulher na sociedade: uma reflexão a partir de o Segundo Sexo de
}

\section{Simone de Beauvoir}

Women's space in society: a reflection from the Second Sex from Simone de Beauvoir

\author{
Andressa Bessa Machado Lima \\ Pós-Graduanda em Direitos Humanos e Garantias Fundamentais (UNEMAT). \\ E-mail: andreessabessa@gmail.com
}

Eliete Nunes da Silva

Graduanda na Universidade do Estado de Mato Grosso (UNEMAT).

E-mail: elietenunessilva1@gmail.com

\author{
Sara Mainardi \\ Graduanda na Universidade do Estado de Mato Grosso (UNEMAT). \\ E-mail: mainardioliveira@gmail.com \\ Suzely Ferreira da Silva \\ Graduanda na Universidade do Estado de Mato Grosso (UNEMAT). \\ E-mail: suzyferreira404@gmail.com
}

Resumo: Este artigo busca analisar, através da obra de Simone de Beauvoir: O segundo sexo, o espaço da mulher na sociedade. A obra foi estudada na disciplina de Filosofia Contemporânea I ofertada no III semestre do curso de Licenciatura em Filosofia da Universidade do Estado de Mato Grosso - UNEMAT realizado no Campus Universitário do Médio Araguaia/Núcleo Pedagógico de Vila Rica. A obra tem por objetivo expor as dificuldades enfrentadas pelas mulheres no decorrer da história até a contemporaneidade, com a intenção de destacar a luta e sua coragem frente a uma sociedade construída pelos homens e para os homens, destacando o nascimento de muitos direitos conquistados pelo sexo feminino. Sendo assim, esse texto aborda o movimento feminista e a sua importância diante de todo processo de busca por respeito pelo segundo sexo, expondo um olhar sobre o que significava ser mulher, sob a ótica de como a mulher era vista e o que esperavam dela, comparando-se com os dias atuais. Usando Simone de Beauvoir como referência de personalidade feminina, como alguém que alcançou um espaço valioso no campo dos estudos acadêmicos de cunho teórico sobre a compreensão da história das mulheres, sobretudo a abordagem do papel das mulheres no mercado de trabalho. Vale destacar que esse artigo se trata de estudo de cunho bibliográfico em fase parcial no que tange aos elementos filosóficos e históricos da temática contida na obra: $O$ segundo sexo, autoria de Simone de Beauvoir.

Palavras-chave: Alteridade Masculina; Feminismo; Igualdade; Luta; Sociedade.

Abstract: This article analyzes, through the work of Simone de Beauvoir: The second sex, the space of women in society. The work was studied in the discipline of Contemporary Philosophy I offered in the third semester of the degree course in Philosophy of the State University of Mato Grosso - UNEMAT held at the University Campus of Middle Araguaia / Pedagogical Center of Vila Rica. The work aims to expose the difficulties faced by women throughout history until contemporary times, with the intention of highlighting the struggle and their courage in a society built by men and for men, highlighting the birth of many rights conquered by sex. feminine. Thus, this text addresses the feminist movement and its importance in the 
face of the search for respect for the second sex, exposing a look at what it meant to be a woman, from the perspective of how women were viewed and what they expected of her, compared to the present day. Using Simone de Beauvoir as a reference for female personality, as one who has gained valuable space in the field of academic studies of a theoretical nature on understanding women's history, especially addressing the role of women in the labor market. It is noteworthy that this article is a study of early bibliographic nature regarding the philosophical and historical elements of the theme contained in the work: The second sex, authored by Simone de Beauvoir.

Keywords: Male Otherness; Feminism; Equality; Fight; Society.

\section{Introdução}

Em primeiro momento torna-se essencial conhecer um pouco sobre a obra de Simone de Beauvoir $O$ segundo sexo, para fazer uma ligação entre as ideias da escritora e o leitor. A obra foi publicada em 1949 e traz um conjunto de ideias que relatam a luta contra o desrespeito com a mulher e, além de tratar de assuntos históricos e sociais, trata-se também de assuntos biológicos e filosóficos. É uma obra considerada de extrema importância para os estudos direcionados a compreensão histórica do movimento feminista, porque explica a formação da personalidade feminina, uma vez que revela a forma como a sociedade sempre enxergou e esperou da mulher e como a identidade feminina vem se definindo ao longo da história.

Logo, a leitura da obra: $O$ Segundo Sexo, faz-se necessária frente a necessidade das mulheres entenderem a sua situação. A condição da mulher é estar em uma determinada posição social, enquanto que os homens de forma contrária, não necessitam: "um macho" é um homem; mulher é o que desvia do ser "homem". Dessa forma, as mulheres têm que redefinir suas posições sociais.

A obra de Simone de Beauvoir, aborda a condição de que a mulher sempre foi vista como o sexo frágil e no discorrer da obra, há uma crítica em relação a isso. O homem, desde que nasce é percebido como um ser soberano. Biologicamente falando, o homem nasce e há um certo tipo de reverência sobre suas partes genitais, sendo exaltado todo o poder de ser macho; sobre a mulher, por sua vez, há um certo mistério: seu sexo a diminui num espaço de ser apenas uma menina, capaz de brincar de boneca e se preparar desde cedo para ser uma boa esposa, mãe e dona de casa.

Pertencer ao segundo sexo implica em uma visão social e cultural, colocando as mulheres como objeto do "sexo". Nesse diapasão, sabe-se que é dada uma ênfase, principalmente no corpo e na sexualidade das mulheres. De modo contrário, o homem é visto como o primeiro e isso também está relacionado às suas capacidades de conhecimento. 
Todavia, para a fêmea é atribuído o lugar do outro - o inferior. E é sabido que vivemos numa sociedade onde tudo que é diferente torna-se objeto negativo.

Para tanto é imprescindível, sob o ponto de vista teórico, buscar-se a resposta para o seguinte questionamento: por que as mulheres se tornaram o segundo sexo e estão na posição de outro? Na explicação de Beauvoir, a resposta estaria na lógica da divisão da consciência em self e "outro", porque o self é quem define a si mesmo pela demarcação de si em relação ao outro. Isso acontece, pois o self tem mais poder. Portanto, ele poderá tornar o outro "outro", colocando ele/ela sempre na posição de outro. E, é o que os indivíduos e as sociedades contemporâneas fazem (eu e o outro, nós e outros).

Não podemos perder de vista, nos estudos sobre categorias sociais, que as mulheres pertencem ao grupo de minorias assim como os negros e etc. A questão é: as mulheres sempre estiveram com os homens, por conseguinte as mulheres não têm uma história "comum" como os negros ou os judeus, portanto, as mulheres não se constituíram como um grupo social, como é caso das outras minorias. Para Beauvoir, a organização social das mulheres está começando agora, quando as mesmas passam a recusarem a condição de serem o outro.

Nessas condições, faz-se necessário trilharmos pelo contexto histórico, econômico, social e cultural em que vivia Beauvoir quando escreveu a obra: O Segundo Sexo - na França, primeira metade do século $\mathrm{XX}$, quando as mulheres tinham recentemente conquistado o direito ao voto; quando o aborto era ilegal e passível de punição com pena de morte e quando estavam sob as consequências da Segunda Guerra Mundial. Sendo que a crise econômica fornecia um grande mercado para o escoamento das armas, do equipamento e das munições nos anos de 1937 a 1938 nos Estados Unidos, Inglaterra, França e outros.

Situação essa que promoveu o grande salto (um aumento extraordinário) dos meios de destruição e aniquilamento em massa das forças produtivas dos países capitalistas, dos continentes europeu e asiático. Os Estados Unidos movimentaram boa parte do crescimento das produções, local que careceu de forças produtivas no período pós-guerra, atuando aquém do que eram acostumados (HOBSBAWM,1995).

Assim, podemos dizer que Simone de Beauvoir pensava sob a necessidade dos homens e mulheres trabalharem juntos para que a diferença biológica não fosse obstáculo, no sentido de construir uma relação respeitosa entre homens e mulheres. No que se refere às relações sociais, deveriam ser respeitadas com igualdade, mesmo havendo desigualdade. O cenário já vislumbrava que a guerra trouxera enormes lucros aos monopólios e aumentou ainda mais, a desigualdade social e as contradições de classe, remetendo às ideais de que as mulheres 
precisavam urgentemente lutar pelos direitos de serem inseridas no mercado de trabalho, sob as mesmas condições postas aos homens.

Em outro giro é importante destacar que o feminismo não surgiu com as ideias revolucionárias de Simone de Beauvoir, na história existem muitos relatos de mulheres que buscaram por igualdade entre os gêneros ou, pelo menos, buscaram acabar com o fato de serem sempre subjugadas, vítimas da violência tanto física como psicológica. Existiram muitas mulheres antes dessas que, na contemporaneidade, continuaram na luta, pois é fato que a desigualdade ainda existe entre os sexos.

O feminismo surgiu com a ausência do medo de ser diferente, numa sociedade dominada por costumes conservadores. Muitas mulheres se mostraram como exemplo de inspiração, abrindo caminho para o que hoje já foi conquistado: igualdade política, social, educativa, etc. Mesmo sendo obrigadas, ao longo de muito tempo, a se casarem e trabalharem em seus lares, servindo seus maridos e cuidando dos filhos, elas participaram de muitas mudanças no mundo.

O feminismo existiu em vários contextos da história. Simone de Beauvoir surge no contexto contemporâneo e, por isso, é considerada como referência do feminismo, da tomada da consciência das mulheres no que tange à opressão do patriarcado. A partir de suas ideias, muitas mulheres começaram novamente reivindicar a liberdade e igualdade, no que diz respeito as mudanças sociais, políticas e educativas que estão hoje ao alcance dessa nova geração de mulheres.

Esse "novo" feminismo surge com a intenção de eliminar a noção de inferioridade da mulher em relação ao homem. Beauvoir julgava ser muito importante por ser mulher, para ela a formação do ser humano se dava graças a presença feminina: vinham as mães, tias, professoras, avós, mulheres que faziam história e somente depois, os homens. Em um trecho de sua obra: $O$ Segundo Sexo, ela transcreve. In Albis:

\begin{abstract}
Ora, o que define de maneira singular a situação da mulher é que, sendo, como todo ser humano, uma liberdade autônoma, descobre-se e escolhese num mundo em que os homens lhe impõem a condição do Outro. Pretende-se torná-la objeto, votá-la à imanência, porquanto sua transcendência será perpetuamente transcendida por outra consciência essencial e soberana. O drama da mulher é esse conflito entre a reivindicação fundamental de todo sujeito, que se põe sempre como o essencial, e as exigências de uma situação que a constitui como inessencial. Como pode realizar-se um ser humano dentro da condição feminina? (BEAUVOIR, 2016, p. 23).
\end{abstract}

Ela faz uma análise profunda sobre a opressão que a mulher sempre passou. A mulher sempre está se submetendo a servir o outro, tendo sua identidade determinada pelo 
homem e nunca por si mesma. Ao dizer que: "Não se nasce mulher, torna- se mulher", fazse uma crítica como a mulher é inserida na sociedade ou, pelo menos, era. $\mathrm{O}$ fato de ter nascido mulher, biologicamente falando, não quer dizer nada, porque a sociedade sempre teve uma forma de vida pronta para o sexo feminino.

Nesse sentido, nos questionamos, qual o espaço da mulher na sociedade?

\section{A mulher como sujeito de sua própria existência}

A partir dos discursos apresentados na obra, evidencia-se a necessidade de traçarmos um panorama de como tem sucedido a vida das mulheres na sociedade desde os tempos longínquos, dando ênfase à formação do sujeito.

Segundo Beauvoir, a figura do feminino é abordada por meio de um sujeito que não é o que a representa, mas sim outro: o masculino. $\mathrm{O}$ homem, desde sua infância é ensinado pelos pais e também pela sociedade a serem livres. Possuem essa autonomia de empreender, inventar, ousar.

Enquanto isso, para as mulheres, há um conflito entre sua existência autônoma e seu ser - o outro. Aprendem que para agradar é preciso procurar agradar, fazer-se objeto, renunciando, deste modo, a sua autonomia. São tratadas como bonecas vivas e recusamlhe a dar essa liberdade. Fecham-se um círculo vicioso no qual quanto menos a menina exercer sua liberdade para compreender, aprender e descobrir o mundo, menos encontrará nele recursos e menos ousará afirmar-se como Sujeito.

Ao esmiuçar a história do feminino, Beauvoir concluiu que ela envolve dominação, submissão e dependência. No cenário pós-guerra, o casamento é o componente chave de como essa condição é mantida e como essa liberdade feminina é coibida. É no casamento que se agrega as funções de mãe, esposa e dona de casa, este é o principal destino oferecido para as mulheres. No segundo volume de $\mathrm{O}$ segundo sexo, ela escreve o seguinte, "O destino que a sociedade propõe tradicionalmente à mulher é o casamento. Em sua maioria, ainda hoje, as mulheres são casadas, ou foram, ou se preparam para sê-lo, ou sofrem por não sê-lo, (BEAUVOIR, v II, 2016, p. 185).

Sob essa ótica, pode-se perceber que o destino é um conceito dado de que não há outra escolha na vivência de qualquer mulher que não seja arrumar um marido, construir uma família e cuidar do lar. Atualmente, isso ainda acontece, entretanto, acontecia com uma frequência e intensidade muito maior nas primeiras décadas do período pós-guerra, por volta dos anos 50 e 60 . 
O destino aludido por Beauvoir não é colocado pela natureza, já que as funções exercidas pelas mulheres se diversificam de forma gigantesca nas mais variadas culturas, e que muitas vezes nem existem. Ela afirma que atribuir o casamento como destino para as mulheres é uma questão histórica da formação.

No segundo volume, ela demonstra como a educação das meninas as impulsionam a abandonar as atividades inovadoras e produtivas, e como são desencorajadas a formarem uma personalidade própria e independente. Tudo isso para achegar a um ideal de feminilidade e depois esperarem por um casamento. Beauvoir então escreve: "Durante toda a infância, a menina foi reprimida e mutilada (...). De uma maneira mais ou menos velada, sua juventude consome-se na espera. Ela aguarda o Homem" (BEAUVOIR, v II, 2016, p. 75).

Sabe-se que o casamento também faz parte do homem e Beauvoir, em nenhum momento, rejeitou esse fato. Porém, há uma imensa diferença comparada a mulher: "nenhum jovem, entretanto, considera o casamento seu projeto fundamental. O êxito econômico é que dará sua dignidade de adulto: pode implicar o casamento (...) mas também excluí-lo" (BEAUVOIR, v II, 2016, p. 191). Dessa forma, é sensato dizer que o casamento não intervém na vida do homem com o mesmo encargo que influencia a vida da mulher. Os estudos e carreiras profissionais, para os homens, são propostos como prioridades e, para a mulher, é proposto o casamento.

Beauvoir via no casamento uma espécie de prisão para a mulher. O casamento trazia uma relação de dependência para os casais. Naquela época, não era normal que a mulher trabalhasse fora. Havia um certo estranhamento com a mulher que tinha um emprego, e quando ela trabalhava era necessário ter autorização de seu marido ou de seu pai. Eles acreditavam que a realização de uma mulher estava ligada ao seu papel de mãe, de esposa e dona de casa. Ficar em casa não significava ficar no conforto.

Preferia-se não saber que o trabalho doméstico era um trabalho repetitivo, cansativo, braçal e não renumerado. Infelizmente, não era reconhecido como um trabalho, mas visto como algo natural. Nessa linha, o trabalho doméstico é chamado por Beauvoir de trabalho clandestino. Apesar de uma modificação formal no conceito de trabalho, parece que não houve uma modificação de como a mulher é vista pela sociedade.

A mulher, neste contexto, não é um ser autônomo. Nega-se à mulher autonomia, nega-se, assim, direitos que a caracterizam como pessoa. Uma pessoa não se caracteriza como uma "coisa", sem autonomia. A história da mulher passa pelo fato, inúmeras vezes comprovado, de ser tratada como o "outro" e não como sujeito de sua própria existência. 
Resume bem esta condição na seguinte passagem citada por Beauvoir: "O corpo do homem tem um sentido em si, abstração feita do da mulher, ao passo que este parece destituído de significação se não se evoca o macho... O homem é pensável sem a mulher. Ela não, sem o homem, (BEAUVOIR, 1980, p.10).

Ela imprimiu no modo de pensar e por razões naturais, que a mulher não é "o segundo sexo" ou "o outro". Além disso, num aspecto sociológico, Beauvoir argumentou que historicamente que as mulheres têm sido tratadas como inferiores e secundárias em relação aos homens e a mulher, pela sua condição é arrastada pela ideologia em que a própria se encontra.

Mulheres do campo, por exemplo, usam da força braçal e retornam aos seus afazeres dentro de casa. Essa ideologia machista de que mulher é mais fraca que homem, vem de sua própria família. A mulher, em determinados casos é usada como objeto. E, infelizmente nesses casos, algumas não possuem consciência que vivem aprisionadas e que precisam se libertar para que possam encontrar o seu lugar como mulher na sociedade.

$\mathrm{Na}$ infância, as meninas em geral, crescem brincando de casinha, boneca, casamento, etc. Percebe-se que a mulher é formada pela e para a sociedade. A sociedade quem faz a criança entender o que é ser mulher sob uma perspectiva totalmente diferente daquela pela qual Beauvoir sempre lutou. Parece algo sem efeito, algo inocente, mas tudo começa pelos brinquedos e brincadeiras.

Há um brocardo popular em que: “O homem é a cabeça e a mulher o coração de um lar". Trata-se, flagrantemente, de uma frase bonita, aparentemente romântica e religiosa, mas, se for analisada com atenção, percebe-se o machismo entrelinhas. O homem quem decide, quem comanda e dá as regras; a mulher é o ser adorável, sensível, com capacidade de apenas amar sem impor ou tomar decisões.

Mais de meio século depois da publicação da obra de Beauvoir, percebe-se, ainda, o patriarcado presente. São nesses detalhes, nessas falas que são ouvidas e aceitas de forma natural que as mulheres se tornam menos autoras da própria história. A menina nasce e é instruída a seguir o exemplo da mãe, e a mãe, na maioria das vezes, é apenas "o coração do lar", a pessoa que ama e cuida da família. Apesar de que o espaço da mulher na sociedade já é bem relevante, porém não é satisfatório.

Constata-se, pois, que mesmo as mulheres tendo conquistado muitos direitos, espaço nos debates políticos, ocupando cargos antes tidos como exclusivo dos homens, melhorando suas condições econômicas, verifica-se que ainda hoje, o arcabouço patriarcal 
se faz presente, mesmo que em alguns momentos se apresente de maneira sutil. Ele molda a sociedade, suas funcionalidades. Ao homem é dado privilégios entendidos como normais, e à mulher limita-se sua liberdade. Para isso, basta citar, como exemplo, a permanência da criminalização da mulher que pratica o aborto, num total controle sobre os direitos reprodutivos da mulher (CUNHA, 2014).

O poder sobre o próprio corpo, por exemplo, ainda é uma luta das mulheres. Em alguns países, o aborto já foi legalizado, porém não no Brasil. Aqui o aborto é aceito em três situações: em caso de risco de vida para a mulher causado pela gravidez, quando a gestação é resultante de um estupro ou se o feto for anencefálico. Por mais absurdo que pareça, muitos indivíduos, ao se colocarem contra o aborto, usam, além de outros, argumentos populares do tipo: "na hora de abrir as pernas foi bom, né?" "É uma vida, não tem culpa de nada. Foi você que não se preveniu".

O machismo está impregnado na sociedade, quando falamos de machismo nos referimos, também a muitas mulheres, as quais não reconhecem as lutas e conquistas que já obtiveram e estão sempre dispostas a apontar o dedo e julgar.

Nessa vertente é primordial falarmos sobre o aborto paterno, enquanto a mulher luta para alcançar direitos sobre o próprio corpo, enquanto ela luta para que não traga um filho ao mundo, a sociedade esquece da figura paterna. Quantas mulheres são abandonadas pelos homens ao descobrirem uma gravidez? Quantas mulheres são incentivadas a abortarem por esses mesmos homens que acusam as feministas de mulheres sem escrúpulos? É exatamente por situações assim, que ainda existe tanta luta. Esses foram alguns exemplos para demonstrar o peso do patriarcado sobre as mulheres.

Recentemente, em uma entrevista para O Globo sobre por que Marta Vieira da Silva (futebolista brasileira que atua como atacante) ganha menos de 1\% do salário de Neymar, uma professora de economia da Ibmec RJ Vívian Almeida mencionou, “O que acontece nessa situação da Marta é o que podemos chamar de "Fardo Mulan" que é quando as mulheres precisam ter ações extraordinárias muito além do que os homens fazem, para assim terem espaço para debater gênero".

Um argumento com um termo que deve ser apropriado por todas as mulheres. $\mathrm{Na}$ atualidade, as mulheres podem debater sobre igualdade de gênero em diversos lugares, em casa, na escola, faculdade, internet, mas, no caso da Marta, é um exemplo sobre uma mulher que teve que lutar muito para estar onde estar, fazer algo descomunal aos olhos da 
sociedade, a fim de conquistar seu espaço e poder discutir gênero no futebol com tanta influência - esse é o efeito do fardo Mulan.

Mas, em pleno século XXI, esse termo não deveria ser algo inacreditável, claro que é algo totalmente certo, apesar de algumas mulheres lançarem mão a muito tempo: mulheres extraordinárias que bancam a casa, cuidam dos filhos sozinhas, mulheres que se reinventam todos os dias. É tudo questão de visibilidade. O espaço e a influência que a Marta conquistou só diz uma coisa: existe muita luta pela frente.

Para alcançar a libertação, Beauvoir acreditava que as mulheres devem reconhecer muitas dessas normas sociais como construções. Só então elas terão a liberdade para escapar de seu contexto e decidir o seu próprio destino. Mas infelizmente, essa ideia parece estar fortemente fixada no inconsciente coletivo. Este, que apesar de não derivar de experiências individuais, necessita de reais experiências para se revelar. E, no caso da mulher como um objeto do homem, a reversão de papéis parece ser desprezível aos egressos da escravidão.

Além disso, a busca pela felicidade, a busca pela liberdade como bem maior é algo que deve ser buscado de qualquer jeito, o legítimo de ter uma vida confortável. A mulher tem dignidade e está naturalmente vocacionada a busca pela felicidade, pois também é um ser reflexivo, e como tal, também representa um obstáculo em busca pela felicidade.

Decidir seu próprio destino, como proposto por Simone de Beauvoir, para muitas, não funciona, porém suas ideias despertaram um desejo de luta e independência. Muitas mulheres são aprisionadas às regras impostas pela sociedade e não buscam sua verdadeira essência. Lidam todos os dias com uma luta com seu próprio "eu”. Beauvoir acreditava e corroboramos com ela que, mulheres devem ser soberanas no que se refere a sua própria existência.

\section{Considerações Finais}

A Luta de Beauvoir se tornou um marco histórico. Muitas lutas semelhantes à dela foi coerente com seu ideal. Essa ideia de que homens e mulheres não podem ocupar o mesmo lugar na sociedade, de que homem tem que ganhar mais, precisa ser extinta do padrão da sociedade. Esses rótulos preconceituosos precisam ser definitivamente excluídos das pessoas, para que cada dia sejam vistas como uma "mulher" e não como um objeto.

O cenário político atual remete a um processo de "acirramento de ideológico", sobretudo para as questões de gênero, uma vez que as pessoas andam sensíveis e, ao mesmo 
tempo, intolerantes às discussões. Não se debate mais as opiniões divergentes, de modo respeitosos. Os argumentos históricos e filosóficos parecem não fazer mais sentido e o que prevalece é o "polemismo vazio", os ataques pessoais, calúnias e acusações sem fundamentos e há quem diz que a surdez é o principal eco. E é sobre esse cenário que devemos refletir no que se refere ao papel do curso de Filosofia, frente aos ataques aos direitos humanos e aos autos índices de violências contra as mulheres presente no cotidiano das sociedades brasileiras.

Socialmente, as mulheres conquistaram seu espaço, mas ainda há aquelas que preferem não ir à luta, talvez, por haver uma subordinação dos comportamentos esperados à mulher, que são dominantes e exprimem os papéis de gênero que são construídos na sociedade, faz com que, em muitos momentos, as classificações de violência existentes não sejam reconhecidas por elas, especialmente, quando nos referimos às mulheres casadas e também àquelas em uniões estáveis, o que acaba por colaborar para que as agressões causadas pelos seus companheiros sejam aceitas como normais (FONSECA; RIBEIRO; LEAL, 2012). Essas preferem apontar o dedo para as que vão, pois estão inconscientes e não percebem que seu lugar é no mundo a fora, que seu lugar é juntamente com milhares e milhares de mulheres que não cessam, que não cansam de serem vistas com bons olhos por todas as pessoas. O desejo pela igualdade ainda está vivo em milhares de guerreiras.

As construções histórias e sociais sobre o gênero influenciam a violência contra mulher, à medida que, as relações de poder presentes nos papéis de gênero, que são impostos a mulher, como a função de ser mãe, esposa, submissa ao homem, reforçam a ideia de que a mulher seria inferior ao homem, que ela deveria ter menos direitos que ele, que a mulher não poderia ter liberdade de escolha sobre seu corpo, suas opiniões e sua vida, naturalizando assim, a visão do poder do homem sobre a mulher, o machismo reinante na sociedade, a discriminação de gênero, o que acaba por contribuir para a perpetuação e, até mesmo, o agravamento dos atos de violência contra as mulheres.

O preconceito ainda ativo nos dias de hoje, não faz com que a luta de Beauvoir tenha sido em vão, e sim, que devemos nos inspirar para que homens e mulheres tenham os mesmos direitos. Não podemos ver com negatividade a luta de Beauvoir, porque foram muitas conquistas. A luta é contínua. Ainda são consideradas seres inferiores aos homens.

A mulher, muitas vezes, não se realiza por meio da criatividade ou do trabalho. Não se realiza socialmente, não se realiza em seus próprios projetos, pois precisam ficar em casa 
cuidando dos afazeres, do marido e dos filhos. Para grande parte da sociedade, esse é o papel das mulheres.

Simone de Beauvoir (2005) acreditava que a existência é um processo contínuo e não se deve viver sem projetos, sem objetivos. O indivíduo deve viver de maneira equilibrada e resistente na sociedade em que está inserido. Não se pode viver de forma abstrata é importante que tenha sentido como uma forma de incentivo e continuidade.

Nesse ínterim, é certo afirmar que as mulheres devem se unir e irem a luta sempre, não devem se contentar com espaços e relacionamentos que não as permitam serem totalmente vistas, ouvidas e sentidas. O feminismo é uma luta para as mulheres, mas devese conscientizar os homens também. Não existe homem feminista, mas existe homem que defende as mulheres em suas lutas, que é contra machistas, que corrige o amigo preconceituoso e que se nega a um meio onde objetificam as mulheres.

Portanto, você pode não querer abortar, pode querer casar e ter filhos, pode optar por não estudar e ser submissa ao seu marido, entre tantas outras coisas, mas é incoerente que você queira forçar outras mulheres a fazer o mesmo. Feminismo é um movimento de luta pela liberdade e direito de decisão. Não há liberdade sem evolução e amor, mas é impossível que haja liberdade e evolução sem democracia, respeito e igualdade.

\section{Referências}

BEAUVOIR, Simone. O segundo sexo: fatos e mitos. 3 ed. - Rio de Janeiro: Nova Fronteira, 2016.

BEAUVOIR, Simone. O segundo sexo: a experiência vivida, volume 2.3 ed. - Rio de Janeiro: Nova Fronteira 2016.

CHALITA, Gabriel. Mulheres que Mudaram o Mundo. 1. ed. --São Paulo: Companhia Editora Nacional, 2005.

CUNHA, Bárbara Madruga da. Violência contra a mulher, direito e patriarcado: perspectivas de combate à violência de gênero. 2014. Disponível em: < http://www.direito. 116 Id on Line Rev. Mult. Psic. V.13, N. 44, p. 97-117, 2019 - ISSN 1981-1179 Edição eletrônica em http://idonline.emnuvens.com.br/id ufpr.br/portal/wpcontent/uploads/2014/12/Artigo-B\%C3\%A1rbara-Cunha-classificado-em7\%C2\%BAlugar.pdf $>$. Acesso em: 25 de setembro de 2019.

FONSECA, Denise Holanda da; RIBEIRO, Cristiane Galvão; LEAL, Noêmia Soares Barbosa. Violência doméstica contra a mulher: realidades e representações sociais. 2012. Disponível em: Acesso em 25 de setembro de 2019. 
GLOBO, O. Porque Marta não tem patrocínio e ganha menos de 1\% do salário de Neymar?. Disponível em: https://oglobo.globo.com/celina/por-que-marta-nao-tempatrocinio-ganha-menos-de-1-do-salario-de-neymar-23746450. Acesso em: 31 de dezembro de 2019.

HOBSBAWM, Eric. Era dos Extremos: o breve século XX: 1914-1991. 2 ed. - São Paulo: Companhia das Letras, 1995. 